\title{
Intensive interdisciplinary outpatient pain management program for chronic back pain: a pilot study
}

This article was published in the following Dove Press journal:

Journal of Pain Research

29 June 2012

Number of times this article has been viewed

\section{Juraj Artner \\ Stephan Kurz \\ Balkan Cakir \\ Heiko Reichel \\ Friederike Lattig}

Department of Orthopaedic Surgery, University of Ulm, RKU, Germany
Correspondence: Juraj Artner

Department of Orthopaedic Surgery,

University of Ulm, RKU, Oberer

Eselsberg 45, 8908I Ulm, Germany

Tel +49 73 II 1775 III

Fax +4973 I I77 I I84

Email j.artner@gmail.com
Background: Chronic back pain is relatively resistant to unimodal therapy regimes. The aim of this study was to introduce and evaluate the short-term outcome of a three-week intensive multidisciplinary outpatient program for patients with back pain and sciatica, measured according to decrease of functional impairment and pain.

Methods: The program was designed for patients suffering from chronic back pain to provide intensive interdisciplinary therapy in an outpatient setting, consisting of interventional injection techniques, medication, exercise therapy, back education, ergotherapy, traction, massage therapy, medical training, transcutaneous electrical nerve stimulation, aquatraining, and relaxation.

Results: Based on Oswestry Disability Index (ODI) and Numeric Rating Scale (NRS) scores, a significant improvement in pain intensity and functionality of $66.83 \%$ NRS and an ODI of $33.33 \%$ were achieved by our pain program within 3 weeks.

Conclusion: This paper describes the organization and short-term outcome of an intensive multidisciplinary program for chronic back pain on an outpatient basis provided by our orthopedic department, with clinically significant results.

Keywords: chronic back pain, intense, multidisciplinary, program, outpatient

\section{Introduction}

Chronic back pain is the most common cause of long-term disability in the middleaged population in most countries. About $20 \%$ of the German population suffers from back pain, and $10 \%$ have pain of high intensity causing functional impairment. ${ }^{1-3}$ Back pain that persists for longer than 3 months is deemed to be chronic. It significantly affects all aspects of life and, because of its multitude of biopsychosociocultural components, is relatively resistant to unimodal therapy regimes. ${ }^{4}$ Together with inpatient and acute care, the special orthopedic pain management program in the Department of Orthopaedics at the University of Ulm provides an intensive interdisciplinary approach to treatment of patients with chronic back pain on an outpatient basis. The purpose of this paper was to present a retrospective analysis and critical evaluation of this program.

\section{Materials and methods}

This retrospective analysis included 160 subjects from a total of 184 patients treated in our special orthopedic pain management program in 2010. There were 70 male and 90 female patients with a minimum duration of back pain of three months and persistence after standard medical treatment, who met the inclusion criteria for the special orthopedic pain management program described below (see Tables 1 and 2). 
Table I Program inclusion criteria

\begin{tabular}{ll}
\hline Age over 18 years & Normal overall fitness \\
Pain duration $>12$ weeks & Compliant with therapy \\
Prior standard treatment & Back pain* \\
\hline
\end{tabular}

Note: *Nonspecific back pain, disc herniation without paresis, facet joint disease, spinal stenosis.

Unlike other pain programs, we do not exclude patients with failed back surgery syndrome or rheumatic disease, and do not set age limits as long as the above-mentioned inclusion criteria are met. Baseline and outcome parameters for pain and disability after three weeks of the program were assessed using the Numeric Rating Scale (NRS) and Oswestry Disability Index (ODI) questionnaires. Patients were asked to complete these questionnaires and were also advised to complete a personal pain diary during the program, whereby pain intensity was rated on the NRS four times per day.

The NRS is a well accepted tool for assessment of the intensity of back pain, with 11 possible grades from 0 (no pain) to 10 (maximal pain). ${ }^{5}$ The ODI is also a well accepted outcome instrument used in the management of spinal disorders, and has good validity and reliability. ${ }^{5-8}$ Performance of daily activities influenced by pain is evaluated using a 10-item questionnaire. Patients grade their impairment and pain, and indicate the extent to which pain influences their self-care, lifting, walking, sleeping, standing, sitting, traveling, social activity, and sexual function. Each item is scored on a six-point scale ( $0-5)$. The score for each item is added and divided by the total possible score (50, if all questions were answered). The possible outcome varies between $0 \%$ and $100 \%$ impairment.

The primary research question was whether there was a clinical benefit from this program, as indicated by changes in NRS and ODI scores between baseline and on completion of the program, and if the conservative treatment could achieve a so-called "good outcome", ie a clinically relevant change. We defined a "good outcome" as a minimum clinically important change in pain intensity of at least two points

Table 2 Program exclusion criteria

\begin{tabular}{lll}
\hline $\begin{array}{l}\text { Infection } \\
\text { Severe instability }\end{array}$ & $\begin{array}{l}\text { Anticoagulation } \\
\text { Myelopathy } \\
\text { Pregnancy }\end{array}$ & $\begin{array}{l}\text { Paresis } \\
\text { Weak overall fitness }\end{array}$ \\
$\begin{array}{l}\text { Severe osteoporosis } \\
\text { Age under 18 years }\end{array}$ & $\begin{array}{l}\text { Somatofory during last } \\
\text { Substance abuse }\end{array}$ & $\begin{array}{l}\text { Red flags anamnesis } \\
\text { Noncompliant with } \\
\text { therapy }\end{array}$ \\
Fracture & $\begin{array}{l}\text { Severe cardiopulmonary } \\
\text { change }\end{array}$ & \\
\hline
\end{tabular}

on the NRS and of at least 10 points on the ODI, consistent with previous studies in patients with spinal disorders., ${ }^{9} 10$ Further, our results were compared with the results of other programs reported in the literature.

\section{Special orthopedic pain management program}

Our pain management program was designed for patients suffering from chronic back pain to provide intensive interdisciplinary therapy in an outpatient setting and consists of interventional injection techniques, medication, exercise therapy, back school, ergotherapy, traction, massage therapy, medical training, transcutaneous electrical nerve stimulation, aquatraining, relaxation, and further techniques as described below. The goal is to deliver an intensive combination of activating and relaxing cycles. An individual therapy plan is designed at the beginning of the program for each patient, depending on their disorder, chronification, and other factors, including overall fitness, disability, and comorbidity. We combine group therapy with individualized treatment approaches. If indicated, further psychosomatic exploration and treatment is embarked on.

Our basic pain management team consists of an experienced orthopedic surgeon, who assessed patients twice daily and administered spinal injections as necessary, an anesthetist/algesiologist, and a group of 5-6 experienced physical therapists who provide both individual and group treatments. Each patient's history, treatment program, and progress are discussed by the team, at meetings held 2-3 per week.

The duration of the program is three weeks, and includes work days between 8 am and $5 \mathrm{pm}$. About 3-4 patients who meet the inclusion criteria are added into the program weekly, so the group always consists of 10-12 patients. This protocol allows group treatment to be as intensive as individual therapy. Approximately 185-200 patients are treated each year in our pain management program. The following is an overview of the therapy provided for each patient.

\section{Medical treatment}

The medical component of the program determines the indication for treatment, and includes a baseline examination, documentation, planning of the treatment regime, control and supervision of each patient's progress twice daily, with spinal injection and modification of analgesia as appropriate. In our department, spinal injection procedures are performed by an experienced surgeon, who also heads the program. Approximately 900-1000 epidural injections, 300-400 periradicular injections, and at least 1000 facet joint 
injections are performed per year in our department. The indication for spinal injection is determined by the orthopedic surgeon, who is also the performing interventionalist. The decision is based on daily patient status, pain intensity, physical examination, findings on radiographic and nuclear magnetic resonance imaging, and chronification grade. All spinal injections are performed using computed tomographic or fluoroscopic guidance. Facet joint injections can be performed as part of treatment or to confirm facetogenic pain, as seen in spondyloarthritis, scoliosis, spondylolisthesis, or even osteoporosis. Nerve root injections are performed into the extraforaminal region or via an epidural-perineural approach in cases of nerve root compromise in patients with disc herniation, lateral spinal stenosis, or failed back surgery syndrome. Sacroiliac joint injections are performed in patients with low back pain and glutalgia originating from the sacroiliac joints as seen in seronegative spondyloarthropathy, sacroiliac dysfunction, limb length discrepancy, or after hip joint arthroplasty. For epidural injections into the cervical or lumbar spine we prefer the interlaminar approach in cases of spinal stenosis, unisegmental or multisegmental disc herniation, failed back surgery syndrome, and osteochondrosis. In cases of severe narrowing of the interlaminar gap (severe degeneration, osteoporosis, following fusion surgery) we use a transforaminal or epidural sacral approach. We limit the number of injections and exposure to radiation and corticosteroids (maximum 100-120 mg triamcinolone), performing 2-8 injections per patient. For therapeutic purposes, we use a combination of triamcinolone (20-40 mg per injection) and ropivacaine. When performed for diagnostic purposes, only ropivacaine is used. We use pulsed fluoroscopic guidance to limit radiation exposure in image-guided injections, and low-dose protocols in computed tomography guidance.

During the program, the medication intake of each patient, especially analgesics, is analyzed and modified as necessary by the physician, depending on pain intensity, comorbidities, side effects, and concomitant medication. We use a standardized pain diary to monitor improvement on the 10-point NRS four times per day. A pain diary also identifies circadian variation in pain more easily. First-line treatment of nonopioid analgesics and myorelaxants is provided when lower pain intensity is reported. In cases of high intensity pain, we perform spinal injections, add opioid analgesics to the medication, or even perform morphine rotation. Concomitant antidepressants or anticonvulsants are used in rare cases. In most cases, there is a decrease in analgesics intake during the program, but there are also cases when analgesics are changed, modified, or added.

\section{Exercise therapy}

Most studies of exercise treatment have found good results for reduction in intensity of back pain, ranging between $10 \%$ and $50 \% .{ }^{11}$ Exercise improves range of motion, muscle strength, posture, cardiovascular endurance, and sensitivity to pain. In our program, patients participate in intensive daily exercise consisting of cycles of physical therapy, medical training therapy, aerobic training, and aquatraining under supervision, followed by relaxation, massage, or spa therapy.

\section{Ergotherapy}

Each patient in our program learns how to adapt his/her workplace and home ergonomics on an individual basis depending on the extent of their disability.

\section{Back education}

Patients participate in an intensive back education program, which improves posture, reduces pain, and teaches them how to avoid overload and pain during activities of daily living.

\section{Physical therapy}

A growing body of evidence indicates the efficacy of physical therapy in the treatment of back pain. Every patient receives an intensive combination of spa therapy, transcutaneous electrical nerve stimulation, fango sheets, massage, manual therapy, stretching exercise, breathing gymnastics, traction, and thermal therapy, depending on the diagnosis and the patient's response. The goals are relaxation and detonization, pain reduction, and increased blood perfusion, in combination with activating cycles of exercise.

\section{Behavioral management}

The purpose of behavioral management is to modify the patient's perception of their pain, to reduce stress, and to learn relaxation techniques. The cycles are integrated twice per week for every patient, but can be varied on an individual basis. Behavioral management is the domain of physiotherapists in a group setting.

\section{Psychosomatic therapy}

Depending on the degree of chronification and psychological cofactors, patients may undergo psychosomatic exploration and therapy in our program. Group psychotherapy is performed by a psychologist specialized in psychosomatic medicine and psychotherapy, focusing on psychosomatic and behavioral therapy, relaxation, and pain perception. The individualized approach is optional, although is used with increasing frequency. Patients are evaluated individually by 
Table 3 Frequency of treatment modalities in our intensive interdisciplinary outpatient pain management program

\begin{tabular}{|c|c|c|c|}
\hline Medical control & $2 \times$ daily & $\begin{array}{l}\text { Behavioral } \\
\text { (relaxation) } \\
\text { therapy }\end{array}$ & $2 \times$ weekly \\
\hline Exercise therapy & $\begin{array}{l}4 \times \text { weekly } \\
(\text { mean I } 2 \times)\end{array}$ & Feldenkrais & $2 \times$ weekly \\
\hline Spinal injections & $\begin{array}{l}\text { Mean 2-8x } \\
\text { injections }\end{array}$ & $\begin{array}{l}\text { Traction } \\
\text { therapy }\end{array}$ & I-5× weekly \\
\hline Back school & $4 \times$ weekly & Electrotherapy & $4-5 \times$ weekly \\
\hline Equipment training (gym) & $4 \times$ weekly & Fango & 4-5× weekly \\
\hline Sport therapy & $4 \times$ weekly & Walking & I× weekly \\
\hline Spa therapy* & $4 \times$ weekly & Ergotherapy & I× weekly \\
\hline Massage & $4-5 \times$ weekly & $\begin{array}{l}\text { Psychosomatic } \\
\text { therapy }\end{array}$ & Variable \\
\hline
\end{tabular}

Note: *Active training therapy in swimming pool.

the psychologist using the standardized interview method devised by Kernberg and, if indicated, are treated in one or two sessions per week. ${ }^{12}$ If further treatment is needed, patients are advised to have further therapy sessions. The treatment regime and the individual frequency of treatments may vary, depending on the degree of disability and actual pain (Table 3).

\section{Statistical analysis}

Data analysis was performed using SPSS version 15 (SPSS Inc, Chicago, IL), IBM software for descriptive statistics, and the Mann-Whitney U-test (confidence interval [CI] 95\% and $\alpha=0.05$ ) to identify any statistically significant differences in NRS and ODI scores for low back pain before and after the program. Twenty-four incomplete datasets were excluded from the study.

\section{Results}

The 160 patients included in this study had a mean age of $57.18 \pm 10.89$ (range 22-82) years. Mean baseline NRS score was $6.03 \pm 1.69(95 \%$ CI, 5.77-6.29). Mean baseline ODI score was $34.39 \% \pm 15.85 \%$ (95\% CI, 31.93-36.85). After treatment, the mean NRS score was $2.00 \pm 1.61(95 \% \mathrm{CI}, 1.75-2.25)$ and the mean ODI score was $24.21 \pm 15.4 \%$ (95\% CI, 21.82-26.60). The mean difference between before and after treatment scores on the NRS was $4.00 \pm 2.01$ points ( $95 \%$ CI, 2.69-4.31), representing a $66.83 \%$ reduction, and a reduction in ODI score of $11.00 \pm 10.97$ points (95\% CI, 9.3-12.7), representing a $33.33 \%$ reduction. Baseline and outcome characteristics are shown in Table 4 (see also Figures 1 and 2).

\section{Complications}

There were no significant complications (eg, infection, paresis, allergic reaction, or arrhythmia) in our patients
Table 4 Baseline and outcome characteristics

\begin{tabular}{llll}
\hline & $\begin{array}{l}\text { Baseline, } \\
\mathbf{n}(\mathbf{C l} \text { 95\%) }\end{array}$ & $\begin{array}{l}\text { Post-treatment, } \\
\mathbf{n}(\mathbf{C l} \text { 95\%) }\end{array}$ & Difference \\
\hline Gender (n) & & & - \\
$\quad$ Male & 70 & & - \\
$\quad$ Female & 90 & & - \\
Age (years) & $57.18(22-82)$ & & $4(66.83 \%)$ \\
NRS & $6.03(5.77-6.29)$ & $2(1.75-2.25)$ & $P<0.000 \mathrm{I}$ \\
(I0-point scale) & & & $\mathrm{II}(33.33 \%)$ \\
ODI (\%) & 34.39 & $24.21(21.82-26.6)$ & $P<0.000 \mathrm{I}$ \\
\hline
\end{tabular}

Abbreviations: $\mathrm{Cl}$, confidence interval; ODI, Oswestry Disability Index, NRS, Numeric Rating Scale.

during the study. The most frequent side effect of intensive exercise therapy was a temporary increase in muscle soreness, often interpreted as pain. This effect was seen on days 3-5 of the first week of therapy. Muscle soreness is self-limiting, and has been well described in other reports of intensive exercise treatment. ${ }^{11}$ From the 24 incomplete datasets, two withdrawals due to respiratory tract infection were identified, along with two exclusions because of pain escalation at examination on the first day of the program. These patients underwent intensive hospital care for further diagnostics and intravenous analgesia. Vasovagal reactions to pain injections occurred in five patients, as well as hypertonia. These side effects were self-limiting.

\section{Discussion}

This retrospective analysis indicates that good improvement in pain and functionality, as reflected by a change in visual analog scale score of 4 points $(66.83 \%)$ and a change in ODI score of 11 points (33.33\%), was achieved by patients in our pain program within three weeks. We did not analyze parameters like spinal mobility, and did not follow them up, because they are not representative. Our program also includes patients with ankylosing spinal diseases, such as diffuse idiopathic skeletal hyperostosis and spondylitis ankylosans, and although we achieve good results for pain and functionality in these conditions, spinal mobility parameters would not be able to be improved in such patients. The gender distribution ( 90 females, 70 males) is consistent with the known fact that spinal disorders are more common in women than in men. ${ }^{13}$

To define a good clinical result in pain patients is difficult. Individual patient factors like expectations, age, pain intensity, diagnosis, comorbidity, and functional impairment all play a role. The principal target of interdisciplinary treatment is to increase function in the patient's occupational and private life, but each patient has different priorities 

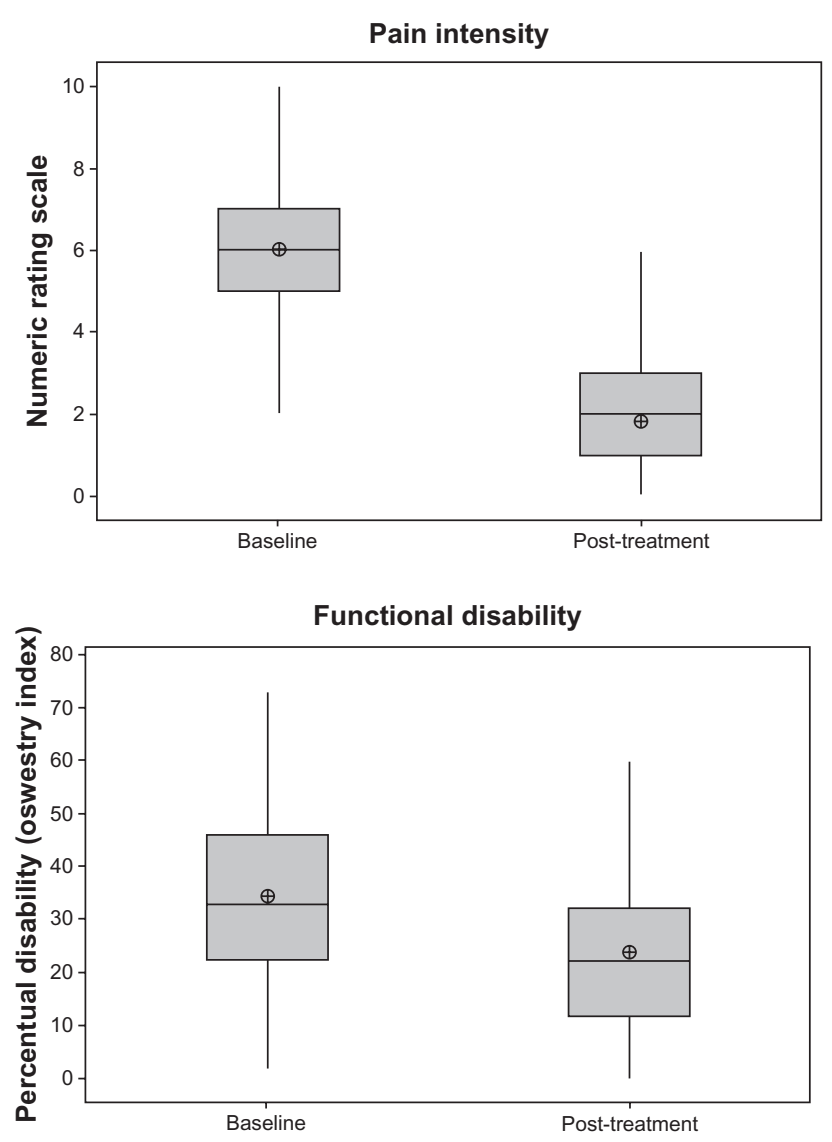

Figure I and 2 Baseline to post-treatment improvement of pain and disability. Box plot legend: Upper whisker - Extends to the maximum data point; interquartile range box, middle $50 \%$ of the data; Top line-Q3 (third quartile). $75 \%$ of the data are less than or equal to this value. Middle line - Q2 (median); Target - mean value; Bottom line-QI (first quartile). $25 \%$ of the data are less than or equal to this value. Lower whisker - Extends to the minimum data point.

regarding functional impairment. While younger patients consider restoration of work status, social activities, travel, and even sexual function to be important, older people are more likely to value basic functioning in the home and being able to walk. Most of these items are covered in the ODI, but the relevant data in the international literature regarding clinically significant change are inconsistent. While many researchers suggest a $4-10$-point difference to determine significant change, there are also studies suggesting a range of $10.5-15$ points. ${ }^{14-18} \mathrm{~A}$ raw change of -1.74 on the NRS, corresponding to a change of $-27.9 \%$, was reported by Farrar et al as clinically significant improvement. ${ }^{17}$ Based on statistical research, Hagg et al defined a minimal clinically significant reduction in ODI of approximately 10 points, whereas Mannion et al identified an 18\% reduction of the baseline score (defined for spinal surgery outcomes) and a change of approximately 20 points on a 100 -point visual analog scale, which corresponds to a minimal change of 2 points on the 11-point scale NRS scale. ${ }^{10,19}$ Maughan and
Lewis reported the smallest detectable change to be 2.4 points for the NRS and 17 points for the ODI, which is comparable with the clinical interpretation by an expert consensus panel proposing 2 points for the NRS and 10 points for the ODI. ${ }^{5,9,20}$ Fritz and Irrgang proposed that a 6-point difference in the ODI was the minimal clinically important difference. ${ }^{15}$ Childs et al concluded from their calculations that a 2-point change on the NRS is necessary to exceed statistical error and to be considered clinically meaningful. ${ }^{21}$ According to IMMPACT (Initiative on Methods, Measurement, and Pain Assessment in Clinical Trials), a $10 \%-20 \%$ reduction in the baseline NRS score reflects a minimal important change and a reduction of $30 \%$ or more represents a clinically important difference. ${ }^{22}$ The results seen in our intensive multidisciplinary outpatient program cohort fulfilled all of these criteria. There is a large amount of literature about the efficacy of conservative treatment for chronic back pain, as shown in Table 5 .

Evidence for the beneficial effects of intensive interdisciplinary programs on pain, functionality, and return to work is accumulating. Intensive ( $>100$ hours) daily interdisciplinary rehabilitation (defined as an intervention with a physical component plus a psychological, social, and/or occupational component) seems to be superior to noninterdisciplinary rehabilitation or usual care for improving short-term and long-term functional status and pain, return to work, and reducing intake of pain medication. ${ }^{41-47}$ Less intensive interdisciplinary approaches seem to be less associated with improvement in pain or function compared with noninterdisciplinary outpatient rehabilitation or usual care. ${ }^{48}$

Intensive interdisciplinary treatment has both benefits and limitations. Despite its efficacy, there is still a lack of standardization regarding the frequency and amount of treatment needed. The Agency for Healthcare Research and Quality has summarized the components of interdisciplinary treatment as consisting of four main elements, ie, medical care, physical reconditioning, behavioral medicine, and education, with team meetings and individualized therapies, undertaken for two hours twice a week to eight hours on five days a week for six weeks. ${ }^{49,50}$ In the literature, intensive programs are understood to include more than 100-120 hours of therapy, but there is no standard terminology. One major benefit of interdisciplinary pain programs lies in the biopsychosocial approach, which focuses on functional restoration and combines a large amount of treatment modalities. Also, larger groups of patients can undergo this therapy in contrast to surgical or unimodal conservative 
Table 5 Sample comparison of efficacy of conservative therapies in chronic low back pain

\begin{tabular}{|c|c|c|c|c|}
\hline Author & Description & $\begin{array}{l}\text { Baseline } \\
\text { NRS/ODI }\end{array}$ & $\begin{array}{l}\text { Post-treatment } \\
\text { NRS/ODI }\end{array}$ & $\begin{array}{l}\text { Difference } \\
\text { NRS/ODI }\end{array}$ \\
\hline Descarreaux et $\mathrm{a}^{23}$ & Individual home exercise program $(\mathrm{n}=10,6$ weeks $)$ & $3.1 / 25.6$ & I.7/I5.4 & $-45.2 \% /-39.8 \%$ \\
\hline \multirow[t]{4}{*}{ Mannion et $\mathrm{al}^{24}$} & Comparative 3 groups (twice weekly, 12 weeks) & & & \\
\hline & Active physiotherapy & $4.4 / \times$ & $3.2 / \times$ & $-27.3 \% / x$ \\
\hline & Training devices & $4.2 / \times$ & $3.1 / \times$ & $-26.2 \% / \times$ \\
\hline & Low-impact aerobics & $4.1 / x$ & $3.4 / \times$ & $-\mid 7.1 \% / \times$ \\
\hline \multirow[t]{3}{*}{ Murtezani et a ${ }^{25}$} & Comparative ( 2 groups, 12 weeks) & & & \\
\hline & High-intensity exercise & $6.0 / 31$ & $2.0 / 25.8$ & $-66.7 \% /-49 \%$ \\
\hline & Passive treatment (heat, TENS, ultrasound) & $6.1 / 30.7$ & $6.0 / 30.6$ & $-1.64 \% /-0.33 \%$ \\
\hline Brinkhaus et $\mathrm{a}^{26}$ & Acupuncture $(12 \times, 8$ weeks $)$ & & & $-28.7 \% / \times$ \\
\hline Borman et $\mathrm{al}^{27}$ & Physical therapy and traction (10×, 2 weeks) & $5.7 / 32.3$ & $3.8 / 26.8$ & $-33.3 \% /-17.03 \%$ \\
\hline Frost et $\mathrm{a}^{28}$ & Fitness program with back school (6 months) & $2.1 / 23.6$ & $1.2 / 17.6$ & $-28 \% /-25 \%$ \\
\hline $\begin{array}{l}\text { Van der Velde } \\
\text { and } \text { Mierau }^{29}\end{array}$ & Aerobic and flexibility exercise program ( 6 weeks) & & & $-31 \% /-33 \%$ \\
\hline Rydeard et $\mathrm{al}^{30}$ & Pilates exercise ( $3 \times$ per week, 4 weeks) & & & $-20.4 \% / x$ \\
\hline Waagen et $\mathrm{al}^{31}$ & Spinal manipulative treatments ( 2 weeks, reviews) & & -0.5 to $-1 / x$ & \\
\hline \multicolumn{5}{|l|}{ Gibson et $\mathrm{al}^{32}$} \\
\hline \multicolumn{5}{|l|}{ Triano et $\mathrm{a}^{33}$} \\
\hline \multicolumn{5}{|l|}{ Assendelft et al ${ }^{34}$} \\
\hline Tsauo et $\mathrm{al}^{35}$ & Functional training program (3 months) & $11.8 / 22$ & $5.6 / 16$ & $-53.1 \% /-27.3 \%$ \\
\hline Rainville et $\mathrm{al}^{36}$ & Spine rehabilitation program $(2-3 \times$ per week) & & & $-28 \% /-25 \%$ \\
\hline Sahin et $\mathrm{al}^{37}$ & Back school program ( $n=73,2$ weeks) & $5.69 / 54.5$ & $4.91 / 41.01$ & $-|3.7 \%|-24.8 \%$ \\
\hline Luk et $\mathrm{al}^{38}$ & $\begin{array}{l}\text { Multidisciplinary rehabilitation program } \\
\text { ( } \mathrm{n}=28,14 \text { weeks, follow-up } 6 \text { months) }\end{array}$ & $3.8 / 42$ & $22 / 29$ & $-44 \% /-31 \%$ \\
\hline Hazard et a $\left.\right|^{39}$ & $\begin{array}{l}\text { Strength and endurance training, stretching, } \\
\text { and behavioral support ( } \mathrm{n}=59,3 \text { weeks) }\end{array}$ & & & $-26 \% / x$ \\
\hline Edwards et a $\left.\right|^{40}$ & $\begin{array}{l}\text { Resistive training, work hardening and manual } \\
\text { treatment ( } n=54,4 \text { weeks) }\end{array}$ & & & $-30 \% / x$ \\
\hline
\end{tabular}

Abbreviations: ODI, Oswestry Disability Index, NRS, Numeric Rating Scale; TENS, transcutaneous electrical nerve stimulation.

treatments, making this therapy cost-effective, especially in patients with significant functional impairment. ${ }^{41} \mathrm{On}$ the other hand, to provide individual therapy, group sizes must be limited. Another limitation is the age of the patient. Most intensive treatments focusing on functional restoration include only patients of working age, for whom the initial target is reintegration into the workforce. We do not exclude geriatric patients from our program. Despite this, overall fitness of our patients remains a limiting factor, and so excludes many elderly patients. Other limitations concern patients who are immigrants with language problems, who are not suitable for behavioral or educational programs in this setting. There has been an increase in this patient group, as well as the need for an interdisciplinary approach.

We have also seen an increase in uncontrolled intake of analgesics among patients suffering from back pain. An alarming long-term intake of nonsteroidal anti-inflammatory analgesics is seen, especially in the elderly population, who have an increased risk of potential side effects with these agents. According to our results, and comparing them with those in the current literature, the short-term results of our interdisciplinary outpatient pain management program indicate a clinically significant improvement in pain and functionality.

\section{Conclusion}

Despite their efficacy, interdisciplinary treatments for back pain still lack standardization regarding the amount and intensity of the therapy regime. The use of spinal injections is a good example. Based on our experience, we use spinal injections as supportive therapy and to confirm whether pain is facetogenic, discogenic, or radicular, or if it is originating from the sacroiliac joints. Despite the controversial evidence, we see positive results in terms of symptom control in most patients when the indication is strictly controlled. Another example is the intensity of the psychologic/psychosomatic treatment. We are seeing an increasing frequency of individual psychological approaches in addition to group therapy, which is well accepted in most cases. Also, a balance in the proportion of active and passive treatments plays an important role in interdisciplinary therapy. Patients suffering from chronic pain prefer passive treatment, which is helpful in 
symptom control. On the other hand, one of the main aims of treatment is to increase the activity levels of the patient, which can only be achieved with adequate active therapies.

Here we describe an intensive outpatient interdisciplinary program for the management of chronic back pain which appears to have good short-term clinical results in terms of reduction in functional disability and pain relief. The limitations of this study are its retrospective nature, the lack of a control group, and the short duration of follow-up. However, one important advantage is the inclusion of elderly patients suffering from chronic back pain. Further investigation is needed to define the long-term results, improvement of isolated spinal disorders, interindividual differences in pain ratings, and their dependence on chronification, age, gender, occupation, coping strategies, fear-avoidance beliefs, and possibly immigration status.

\section{Disclosure}

The authors report no conflicts of interest in this work.

\section{References}

1. Bellach BM, Ellert U, Radoschewski M. Epidemiologie des Schmerzes Ergebnisse des Bundes- Gesundheitssurveys 1998 (Epidemiology of pain: Results of a national health-survey 1998). Bundensgesundheitsblatt - Gesundheitsforschung - Gesundheitsschutz. 2000;43:424-431. German.

2. Schmidt CO, Kohlmann T. What do we know about the symptoms of back pain? Epidemiological results on prevalence, incidence, progression and risk factors. Z Orthop Ihre Grenzgeb. 2005;143:292-298. German.

3. Eckardt A. Praxis LWS-Erkrankungen: Diagnosis und Therapie. (Disorders of the lumbar spine: diagnosis and treatment) Heidelberg, Germany: Springer Medizin Verlag; 2011:1.1; 2-3.

4. Turk DC. Clinical effectiveness and cost-effectiveness of treatments for patients with chronic pain. Clin J Pain. 2002;18:355-365.

5. Maughan EF, Lewis JS. Outcome measures in chronic low back pain. Eur Spine J. 2010;19:1484-1494.

6. Fairbank JC, Pynsent PB. The Oswestry disability index. Spine. 2000;25:2940-2952.

7. Bombardier C. Outcome assessment in the evaluation of treatment of spinal disorders. Spine. 2000;25:3100-3103.

8. Junge A, Mannion AF. Questionnaires for patients with back pain. Diagnosis and outcome assessment. Orthopäde. 2004;33:545-552. German.

9. Ostelo RW, de Vet HCW. Clinically important outcomes in low back pain. Best Pract Res Clin Rheumatol. 2005;19:593-607.

10. Hagg O, Fritzell P, Nordwall A; Swedish Lumbar Spine Study Group. The clinical importance of changes in outcome scores after treatment for chronic low back pain. Eur Spine J. 2003;12:12-20.

11. Rainville J, Hartigan C, Martinez E, Limke J, Jouve C, Finno M. Exercise as a treatment for chronic low back pain. Spine J. 2004;4:106-115.

12. Kernberg O. Severe Personality Disorders: Psychotherapeutic Strategies. New Haven, CT: Yale University Press; 1984.

13. Freburger JK, Holmes GM, Agans RP, et al. The rising prevalence of chronic low back pain. Arch Intern Med. 2009;169:251-258.

14. Beurskens AJ, de Vet HC, Koke AJ. Responsiveness of functional status in low back pain: a comparison of different instruments. Pain. 1996;65:71-76.
15. Fritz JM, Irrgang JJ. A comparison of a modified Oswestry low back pain disability questionnaire and the Quebec back pain disability scale. Phys Ther. 2001;81:776-788.

16. Stratford PW, Binkley J, Solomon P, Gill C, Finch E. Assessing change over time in patients with low back pain. Phys Ther. 1994;74:528-533.

17. Farrar JT, Young JP, LaMoreaux L, Werth JL, Poole RM. Clinical importance of changes in chronic pain intensity measured on an 11-point numerical pain rating scale. Pain. 2001;94:149-158.

18. Davidson M, Keating JL. A comparison of five low back disability questionnaires: reliability and responsiveness. Phys Ther. 2002; 82:8-24.

19. Mannion AF, Junge A, Grob D, Dvorak J, Fairbank JCT. Development of a German version of the Oswestry Low Back Index. Part 2: sensitivity to change after spinal surgery. Eur Spine J. 2006;15:66-73.

20. Ostelo R, Deyo R, Stratford P, et al. Interpreting change scores for pain and functional status in low back pain. Spine. 2008;33:90-94.

21. Childs J, Riva S, Fritz J. Responsiveness of the numeric pain rating scale in patients with low back pain. Spine. 2005;30:1331-1334.

22. Dworkin R, Turk D, Wyrwich K, et al. Interpreting the clinical importance of treatment outcomes in chronic pain trials: IMMPACT recommendations. J Pain. 2008;9:105-121.

23. Descarreaux M, Normand MC, Laurencelle L, Dugas C. Evaluation of a specific home exercise program for low back pain. $J$ Manipulative Physiol Ther. 2002;25:497-503.

24. Mannion AF, Müntener M, Taimeta S, Dvorak J. Comparison of three active therapies for chronic low back pain: results of a randomized clinical trial with one-year follow-up. Rheumatology. 2001;40:772-778.

25. Murtezani A, Hundozi H, Orovcanec N, Sllamniku S, Osmani T. A comparison of high intensity aerobic exercise and passive modalities for the treatment of workers with chronic low back pain: a randomized, controlled trial. Eur J Phys Rehabil Med. 2011;47:359-366.

26. Brinkhaus B, Witt CM, Jena $\mathrm{S}$, et al. Acupuncture in patients with chronic low back pain. Arch Intern Med. 2006;166:450-457.

27. Borman P, Keskin D, Bodur H. The efficacy of lumbar traction in the management of patients with low back pain. Rheumatol Int. 2003;23:82-86.

28. Frost H, Klaber Moffet JA, Moser JS, Fairbank JCT. Randomised controlled trial for evaluation of fitness programme for patients with chronic low back pain. Br Med J. 1995;310:151-154.

29. Van der Velde G, Mierau D. The effect of exercise on percentile rank aerobic capacity, pain, and self-rated disability in patients with chronic low back pain: a retrospective chart review. Arch Phys Med Rehabil. 2000;81:1457-1463.

30. Rydeard R, Leger A, Smith D. Pilates-based therapeutic exercise: effect on subjects with nonspecific chronic low back pain and functional disability: a randomized controlled trial. Orthop Sports Phys Ther. 2006;36:472-484.

31. Waagen GN, Haldeman S, Cook G, Lopez D, DeBoer KF. Short-term trial of chiropractic adjustments for the relief of chronic low back pain. Manual Med. 1986;2:63-67.

32. Gibson T, Grahame R, Harkness J, Woo P, Blagrave P, Hills R. Controlled comparison of short-wave diathermy treatment with osteopathic treatment in nonspecific low back pain. Lancet. 1985;1: $1258-1261$.

33. Triano JJ, McGregor M, Hondras MA, Brennan PC. Manipulative therapy versus education programs in chronic low back pain. Spine. 1995;20:948-955.

34. Assendelft WJ, Morton SC, Yu EI, Suttorp MJ, Shekelle PG. Spinal manipulative therapy for low-back pain. Cochrane Database Syst Rev. 2004;1:CD000447.

35. Tsauo JY, Chen WH, Liang HW, Jang Y. The effectiveness of a functional training programme for patients with chronic low back pain a pilot study. Disabil Rehabil. 2009;31:1100-1106.

36. Rainville J, Jouve CA, Hartigan C, Martinez E, Hipona M. Comparison of short- and long-term outcomes for aggressive spine rehabilitation delivered two versus three times per week. Spine J. 2002;2:402-407. 
37. Sahin N, Albayrak I, Durmus B, Ugurlu H. Effectiveness of back school for treatment of pain and functional disability in patients with chronic low back pain: a randomized controlled trial. J Rehabil Med. 2011;43:224-229.

38. Luk KDK, Wan TWM, Wong YW, et al. A multidisciplinary rehabilitation programme for patients with chronic low back pain: a prospective study. J Orthop Surg. 2010;18:131-138.

39. Hazard RG, Fenwick JW, Kalisch SM, et al. Functional restoration with behavioral support: a one-year prospective study of patients with chronic low back pain. Spine. 1989;14:157-161.

40. Edwards BC, Zusman M, Hardcastle P, Twomey L, O'Sullivan P, McLean N. A physical approach to the rehabilitation of patients disabled by chronic low back pain. Med J Aust. 1992;156:167-171.

41. Nagel B, Korb J. Interdisciplinary treatment. Long-lasting, effective and cost-effective. Orthopäde. 2009;38:910-912.

42. Guzman J, Esmail R, Karjalainen K, Malmivaara A, Irvin E, Bombardier C. Multidisciplinary bio-psycho-social rehabilitation for chronic low-back pain. Cochrane Database Syst Rev. 2002;1: CD000963.

43. Guzman J, Esmail R, Karjalainen K, Malmivaara A, Irvin E, Bombardier C. Multidisciplinary rehabilitation for chronic low back pain: systematic review. BMJ. 2001;322:1511-1516.
44. Bendix AF, Bendix T, Vaegtar KV, Lund C, Frolund L, Holm L. Multidisciplinary intensive treatment for chronic low back pain: a randomized, prospective study. Cleve Clin J Med. 1996;63:62-69.

45. Bendix AF, Bendix T, Ostenfeld S, et al. Active treatment programs for patients with chronic low back pain: a prospective, randomized, observer-blinded study. Eur Spine J. 1995;4:148-152.

46. Alaranta H, Rytokoski U, Rissanen A, et al. Intensive physical and psychosocial training program for patients with chronic low back pain. A controlled trial. Spine. 1994;19:1340-1349.

47. Smith MJ. Accountable disease management of spine pain. Spine J. 2011;11:807-815.

48. Tveito T, Hysing M, Eriksen H. Low back pain interventions at the workplace: a systematic literature review. Occup Med. 2004;54:3-13.

49. Agency for Healthcare Research and Quality. Effective healthcare program. Technical brief: multidisciplinary pain programs for chronic non-cancer pain. 2011. Available from: http://www.effectivehealthcare.ahrq.gov/ ehc/products/212/760/TechBrief8_PainProgramsCancer_20110930.pdf. Accessed March 14, 2012.

50. Schatman ME, Campbell A, editors. Chronic Pain Management: Guidelines for Multidisciplinary Program Development. New York, NY: Informa Healthcare; 2007.
Journal of Pain Research

\section{Publish your work in this journal}

The Journal of Pain Research is an international, peer-reviewed, open access, online journal that welcomes laboratory and clinical findings in the fields of pain research and the prevention and management of pain. Original research, reviews, symposium reports, hypothesis formation and commentaries are all considered for publication.

\section{Dovepress}

The manuscript management system is completely online and includes a very quick and fair peer-review system, which is all easy to use. Visit http://www.dovepress.com/testimonials.php to read real quotes from published authors. 